\title{
Kajian Hasil Pengukuran Undercarriage Bulldozer Komatsu D375A-5 di PT. Pama Persada Nusantara site Batukajang
}

\author{
Syaeful Akbar ${ }^{*}$, Wahyu Anhar ${ }^{2}$ \\ ${ }^{1,2}$ Jurusan Teknik Mesin, Politeknik Negeri Balikpapan \\ *email: syaeful.akbar@poltekba.ac.id
}

\begin{abstract}
A role of bulldozer undercarriage component is very important, because exceedingly to affect of bulldozer working performance. Undercarriage component as consumable part that expended $60 \%$ of the total maintenance cost. This component must be replaced if the tier of weathering exceed by factory decided. If act of replacement was late, working performance of bulldozer will be decline, on the other hand if very fast is wasteful. So the accuracy timing for replace undercarriage component is very important. Undercarriage measuring and monitoring program required for monitoring of weathering rate, so that the replacement time can be predicted. In this case, tool and method for measuring must be correct, so that the result of measurement is accurate and can be produced accurate decision.The purpose of this research is for investigate what's the tool and method for measurement of undercarriage component are correct or significant. For examine this circumstance, undertaken by examining the result of data measurement with norm distribution data test. The tool and method for measurement are stated good if the data distribution comply within norm distribution test, or the result of significant value are greater than 0.05. According to norm distribution data test, indicate that not all the tool and method for measuring undercarriage component are accurate or significant. The result of norm distribution data test for component link-pitch, idler, and sprocket are not comply whit norm distribution data requirement or not assured, because significant value for those component are $<0.05$. So further investigation for analyze what is the tool and method for measurement of link-pitch, idler, and sprocket are required.
\end{abstract}

Keywords: measurement, wear, component, undercarriage

\begin{abstract}
Abstrak
Peranan komponen undercarriage pada bulldozer sangat penting, karena sangat mepengaruhi performa kerja dari bulldozer. Komponen undercarriage merupakan consumable part atau komponen habis pakai, yang rata-rata menghabiskan biaya $\pm 60 \%$ dari total maintenance cost. Komponen ini harus diganti jika tingkat keausannya melebihi batas yang ditentukan oleh pabrik. Jika terlambat melakukan penggantian, maka performa kerja akan menurun, dan sebaliknya jika terlalu cepat dilakukan penggantian, maka akan terjadi pemborosan biaya. Oleh karena itu penggantian komponen undercarriage secara tepat sangat penting. Program monitoring pengukuran undercarriage perlu dilakukan untuk memonitor laju tingkat keausan komponen agar dapat diprediksi kapan waktu yang tepat untuk melakukan penggantian. Sudah barang tentu alat dan metode pengkuran harus tepat, agar hasil pengukuran akurat sehingga keputusan yang diambil adalah keputusan yang tepat. Penelitian ini bertujuan menginvestigasi, apakah alat dan metode yang digunakan dalam pengukuran komponen undercarriage adalah tepat dan akurat, dan untuk membuktikannya, dapat dilakukan dengan cara menguji hasil pengukuran yang dilakukan. Jika sebaran data hasil pengukuran berdistribusi normal, maka dapat disimpulkan alat dan metode pengukuran yang dilakukan sudah tepat dan benar. Berdasarkan hasil uji normalitas data terhadap hasil pengkuran komponenn undercarriage menunjukan bahwa alat dan metode pengukuran yang dilakukan mayoritas baik, karena angka signifikannya $>0,05$ sedangkan hasil pengukuran komponen link-pitch, idler, dan sprocket tidak meyakinkan, karena nilai signifikan $<0,05$. Oleh karena itu perlu dilakukan penelitian lebih lanjut, apakah alat atau metodenya yang tidak tepat, ataukah mungkin tingkat keausan yang terjadi pada komponen-komponen tersebut tidak normal.
\end{abstract}




\section{Pendahuluan}

Komponen

undercarriage

pada

bulldozer megang peranan yang sangat penting untuk menghasilkan daya dorong yang kuat dan sangat menentukan performa kerja bulldozer. Komponen ini merupakan consumable part atau komponen habis pakai, yang rata-rata menghabiskan biaya $+50 \%$ dari total maintenance cost. [1] Komponen undercarriage memiliki masa pakai tertentu dan harus diganti jika tingkat keausannya telah melebihi batas limit yang telah ditentukan oleh pabrik. Jika penggantian komponen undercarriage melewati batas waktu yang telah ditentukan, maka performa kerjanya akan menurun, sebaliknya jika terlalu cepat dilakukan penggantian maka tidak efisien atau terjadi pemborosan. Oleh karena itu penggantian komponen undercarriage harus dilakukan secara tepat.

Menentukan waktu penggantian komponen undercarriage secara tepat menjadi hal yang sangat penting. Masing-masing pemegang merek dagang alat berat, telah memiliki program monitoring pengukuran undercarriage. Melakukan pengukuran dan monitoring terhadap tingkat keausan komponen undercarriage diperlukan untuk memastikan besarnya angka keausan akibat adanya benturan atau abrasive [5] sehingga komponen undercarriage dapat diprediksi kapan komponen tersebut harus diganti. Pengukuran minimal dilakukan setiap 6 bulan [3] atau 450 jam operasi. Alat dan metode pengukuran yang digunakan dalam program pengukuran undercarriage menjadi penting, agar hasil pengukuran yang dilakukan menjadi akurat, sehingga keputusan atau tindakan yang dilakukan menjadi tepat dan effisien.

Hingga saat ini belum ada artikel atau publikasi ilmiah yang mengkaji tentang hasil pengukuran undercarriage yang dilakukan dalam program pengukuran monitoring keausan komponen undercarriage. Oleh karena itu, artikel ini disusun untuk mengetahui apakah hasil pengukuran komponen undercarriage yang dilakukan dalam program monitoring pengukuran undercarriage adalah meyakinkan atau dapat dipercaya.

\section{Metoda Penelitian}

\subsection{Metode Pengumpulan Data}

Metode pengupulan data dalam penelitian ini menggunakan data sekunder berupa hasil pengukuran P2U bulldozer Komatsu D375A-5 antara tahun 2013 sampai dengan tahun 2014. Adapun sampel yang digunakan dalam penelitian ini adalah 11 unit bulldozer Komatsu D375A-5 yang dioperasikan di area pertambangan untuk aplikasi mendorong tanah/soil yang dioperasikan oleh PT. Pama Persada Nusantara Site Batukajang.

\subsection{Metode Pengolahan Data}

Data mentah hasil pengukuran Undercarriage sesuai dengan Undercarriage measuring form [5] yang dilakukan setiap + 450 jam operasi, selanjutnya diolah untuk mendapatkan tingkat keausan per jam, dengan menggunakan rumus dalam Persamaan 1. Rumus tersebut digunakan untuk mengetahui tingkat keausan yang terjadi selama durasi pemakaian tertentu. Bagian pembilang merupakan selisih keausan yang terjadi berdasarkan pengukuran keausan sebelumnya terhadap pengukuran keausan sekarang. Bagian penyebut merupakan selisih jam pemakaian saat pengukuran sekarang terhadap jam pemakaian saat pengukuran sebelumnya.

$$
K j=\frac{P o-P i}{H i-H o} \ldots \ldots \ldots \ldots \ldots . .(\text { Pers. } 1)
$$

dimana $K j$ adalah tingkat keausan per jam (mm/jam), Po adalah hasil pengukuran keausan sebelumnya (mm), $P i$ adalah hasil pengukuran keausan sekarang $(\mathrm{mm}), \mathrm{Ho}$ adalah hour meter saat pengukuran sebelumnya (jam), Hi adalah hour meter saat pengukuran sekarang (jam).

Hasil perhitungan tingkat keausan komponen per jam, selanjutnya diuji menggunakan uji normalitas data untuk memastikan apakah sebaran data telah memenuhi syarat normalitas. Berdasarkan [2] 
bahwa Persamaan 2 digunakan untuk menghitung normalitas data.

$f(X)=\frac{1}{\sqrt{2 \pi \sigma}} e^{-(1 / 2)[(X-\mu) / \sigma]^{2}}$

dimana $e$ adalah konstanta matematika (dengan nilai 2,71828), $\pi$ adalah konstanta matematika (dengan nilai 3,14159), $\mu$ adalah rata-rata, $\sigma$ adalah standar deviasi, $X$ adalah nilai inputan $(-\infty<X<\infty)$.

Sebuah hasil pengukuran dapat dikatakan baik atau meyakinkan, jika sebaran data berdistribusi normal. Sedangkan jika sebaran data tidak memenuhi syarat berdistribusi normal, maka perlu dilakukan penelitian lebih lanjut apakah instrument atau metode pengukurannya tidak akurat, [4] atau mungkin terjadi laju tingkat keausan komponen yang tidak normal.

\section{Hasil dan Pembahasan}

\subsection{Pengukuran Link-Pitch}

Berdasakan hasil uji normalitas data terhadap pengukuran komponen link-pitch dapat dilihat pada Tabel 1 .

Hasil uji normalitas data dari sampel uji sebanyak 11 unit, dimana masing-masing unit dilakukan 2 kali pengukuran yakni komponen link-pitch sebelah kiri dan sebelah kanan. Hasilnya menunjukan bahwa hanya ada 4 unit yang nilai signifikannya $>0,05$ atau kurang dari $40 \%$, yang berarti lebih dari $60 \%$ hasil pengukuran tidak memenuhi syarat normalitas data. Dengan demikian hasil pengukuran komponen link-pitch tidak meyakinkan, untuk itu perlu dievaluasi, karena ada kemungkinan terjadi kesalahan pada alat atau metode pengukuran yang digunakan atau mungkin terjadi tingkat keausan yang tidak normal.

Tabel 1. Hasil Uji Normalitas Data Terhadap Pengukuran Komponen Link-Pitch

\begin{tabular}{|c|c|c|c|c|c|c|}
\hline \multicolumn{7}{|c|}{ Tests of Normality } \\
\hline & \multicolumn{3}{|c|}{ Kolmogoroy-Smimov" } & \multicolumn{3}{|c|}{ Shapiro-iuñlk } \\
\hline & Statistic & $d f$ & Sig. & Statistic & $d f$ & Sig. \\
\hline$\overline{D Z 401 \_L}$ & .385 & 3 & . & .750 & 3 & .000 \\
\hline DZ401_R & .385 & 3 & . & .750 & 3 & .000 \\
\hline DZ412_L & .347 & 3 & . & .835 & 3 & .202 \\
\hline DZ412_R & .347 & 3 & . & .835 & 3 & .202 \\
\hline DZ488_L & .385 & 3 & . & .750 & 3 & .000 \\
\hline DZ488_R & .385 & 3 & . & .750 & 3 & .000 \\
\hline DZ452_L & .385 & 3 & . & .750 & 3 & .000 \\
\hline DZ452_R & .385 & 3 & . & .750 & 3 & .000 \\
\hline DZ453_L & .385 & 3 & . & .750 & 3 & .000 \\
\hline DZ453_R & .385 & 3 & . & .750 & 3 & .000 \\
\hline DZ459_L & .246 & 3 & . & .970 & 3 & .667 \\
\hline DZ459_R & .246 & 3 & . & .970 & 3 & .667 \\
\hline DZ460_L & .341 & 3 & . & .846 & 3 & .230 \\
\hline DZ460_R & .341 & 3 & . & .846 & 3 & .230 \\
\hline DZ465_L & .385 & 3 & . & .750 & 3 & .000 \\
\hline DZ465_R & .385 & 3 & . & .750 & 3 & .000 \\
\hline DZ470_L & .320 & 3 & . & .883 & 3 & .334 \\
\hline DZ470_R & .320 & 3 & . & .883 & 3 & .334 \\
\hline DZ476_L & .385 & 3 & . & .750 & 3 & .000 \\
\hline DZ476_R & .385 & 3 & . & .750 & 3 & .000 \\
\hline DZ508_L & .385 & 3 & . & .750 & 3 & .000 \\
\hline DZ508_R & .385 & 3 & & .750 & 3 & .000 \\
\hline
\end{tabular}

\subsection{Pengukuran Link-Height}

Hasil uji normalitas data dari hasil pengukuran komponen link-height dapat dilihat pada Tabel 2.

Tabel 2. Hasil Uji Normalitas Data Terhadap Komponen Link Height

Tests of Normality

\begin{tabular}{|c|c|c|c|c|c|c|}
\hline & \multicolumn{3}{|c|}{ Kolmogorov-Smimov' } & \multicolumn{3}{|c|}{ Shapiro-iúllk } \\
\hline & Statistic & $\mathrm{df}$ & Sig. & Statistic & $\mathrm{df}$ & Sig. \\
\hline DZ401_L & .259 & 3 & . & .959 & 3 & .611 \\
\hline DZ401_R & .385 & 3 & . & .750 & 3 & .000 \\
\hline DZ412_L & .264 & 3 & . & .954 & 3 & .588 \\
\hline DZ412_R & .346 & 3 & . & .838 & 3 & .208 \\
\hline DZ488_L & .385 & 3 & . & .750 & 3 & .000 \\
\hline DZ488_R & .304 & 3 & . & .907 & 3 & .408 \\
\hline DZ452_L & .211 & 3 & . & .991 & 3 & .816 \\
\hline DZ452_R & .385 & 3 & . & .750 & 3 & .001 \\
\hline DZ453_L & .243 & 3 & . & .972 & 3 & .680 \\
\hline DZ453_R & .299 & 3 & . & .914 & 3 & .433 \\
\hline DZ459_L & .178 & 3 & . & .999 & 3 & .956 \\
\hline DZ459_R & .269 & 3 & . & .950 & 3 & .568 \\
\hline DZ460_L & .341 & 3 & . & .846 & 3 & .230 \\
\hline DZ460_R & .198 & 3 & . & .995 & 3 & .871 \\
\hline DZ465_L & .246 & 3 & . & .970 & 3 & .667 \\
\hline DZ465_R & .351 & 3 & . & .826 & 3 & .179 \\
\hline DZ470_L & .328 & 3 & . & .869 & 3 & .294 \\
\hline DZ470_R & .176 & 3 & . & 1.000 & 3 & .982 \\
\hline DZ476_L & .235 & 3 & . & .978 & 3 & .716 \\
\hline DZ476_R & .323 & 3 & . & .879 & 3 & .322 \\
\hline DZ508_L & .269 & 3 & $\cdot$ & .950 & 3 & .568 \\
\hline DZ508_R & .356 & 3 & & .817 & 3 & .156 \\
\hline
\end{tabular}

Dari hasil uji normalitas data untuk komponen link-height menunjukan hasil yang jauh lebih baik. Nilai signifikan yang kurang dari 0,05 hanya ada 3 kali pengukuran. Hasil tersebut menunjukkan bahwa lebih dari $80 \%$ hasil pengukuran memenuhi persyaratan 
normalitas data atau dapat dikatakan bahwa hasil pengukuran link-height meyakinkan.

\subsection{Pengukuran Bushing $O / D$}

Hasil uji normalitas data untuk pengukuran komponen Bushing $O / D$ dapat dilihat pada Tabel 3.

Tabel 3. Hasil Uji Normalitas Data Terhadap Pengukuran Bushing $O / D$

$$
\text { Tests of Normality }
$$

\begin{tabular}{|l|r|r|l|r|r|r|}
\hline & \multicolumn{3}{|c|}{ Kolmogorov-Smimov' } & \multicolumn{3}{|c|}{ Shapiro-iúllk } \\
\cline { 2 - 7 } & Statistic & df & Sig. & Statistic & \multicolumn{1}{c|}{ df } & \multicolumn{1}{c|}{ Sig. } \\
\hline DZ401_L & .177 & 3 &. & 1.000 & 3 & .962 \\
DZ401_R & .383 & 3 &. & .755 & 3 & .012 \\
DZ412_L & .270 & 3 &. & .949 & 3 & .565 \\
DZ412_R & .304 & 3 &. & .908 & 3 & .411 \\
DZ488_L & .385 & 3 &. & .750 & 3 & .000 \\
DZ488_R & .175 & 3 &. & 1.000 & 3 & .999 \\
DZ452_L & .314 & 3 &. & .893 & 3 & .363 \\
DZ452_R & .385 & 3 &. & .750 & 3 & .000 \\
DZ453_L & .302 & 3 &. & .910 & 3 & .419 \\
DZ453_R & .205 & 3 &. & .993 & 3 & .840 \\
DZ459_L & .385 & 3 &. & .750 & 3 & .000 \\
DZ459_R & .323 & 3 &. & .878 & 3 & .319 \\
DZ460_L & .264 & 3 &. & .955 & 3 & .591 \\
DZ460_R & .282 & 3 &. & .936 & 3 & .510 \\
DZ465_L & .331 & 3 &. & .864 & 3 & .280 \\
DZ465_R & .385 & 3 &. & .750 & 3 & .000 \\
DZ470_L & .193 & 3 &. & .997 & 3 & .891 \\
DZ470_R & .299 & 3 &. & .915 & 3 & .434 \\
DZ476_L & .223 & 3 &. & .985 & 3 & .763 \\
DZ476_R & .385 & 3 &. & .750 & 3 & .000 \\
DZ508_L & .188 & 3 &. & .998 & 3 & .912 \\
DZ508_R & .339 & 3 &. & .851 & 3 & .243 \\
\hline
\end{tabular}

Hasil Uji normalitas data terhadap komponen bushing $O / D$ menunjukan bahwa lebih dari $70 \%$ data berdistribusi normal, artinya hasil pengukuran komponen bushing $O / D$ masih bisa diterima.

\subsection{Hasil Pengukuran Grouser Height}

Tabel 4 menunjukkan hasil uji normalitas data terhadap pengukuran grouser height.

Dari hasil uji normalitas data terhadap pengukuran komponen grouser height menunjukan bahwa mayoritas data berdistribusi normal, artinya hasil pengukuran komponen grouser height adalah meyakinkan, atau dengan kata lain alat dan metode pengukuran yang digunakan sudah tepat dan benar.

Tabel 4. Hasil Uji Normalitas Data Terhadap Pengukuran Grouser Height

\begin{tabular}{|c|c|c|c|c|c|c|}
\hline & \multicolumn{3}{|c|}{ Kolmogonov-Smimovi } & \multicolumn{3}{|c|}{ Shapiro-Múlk } \\
\hline & Statistic & $d f$ & Sig. & Statistic & $d f$ & Sig. \\
\hline$\overline{D Z 401 \_L}$ & .265 & 3 & . & .953 & 3 & .583 \\
\hline DZ401_R & .329 & 3 & . & .868 & 3 & .291 \\
\hline DZ412_L & .313 & 3 & . & .894 & 3 & .367 \\
\hline DZ412_R & .246 & 3 & . & .970 & 3 & .668 \\
\hline DZ488_L & .314 & 3 & . & .893 & 3 & .363 \\
\hline DZ488_R & .292 & 3 & . & .923 & 3 & .463 \\
\hline DZ452_L & .292 & 3 & . & .923 & 3 & .463 \\
\hline DZ452_R & .196 & 3 & . & .996 & 3 & .878 \\
\hline DZ453_L & .246 & 3 & . & .970 & 3 & .667 \\
\hline DZ453_R & .212 & 3 & . & .990 & 3 & .812 \\
\hline DZ459_L & .176 & 3 & . & 1.000 & 3 & .988 \\
\hline DZ459_R & .376 & 3 & . & .771 & 3 & .047 \\
\hline DZ460_L & .177 & 3 & . & 1.000 & 3 & .966 \\
\hline DZ460_R & .260 & 3 & . & .958 & 3 & .608 \\
\hline DZ465_L & .344 & 3 & . & .842 & 3 & .219 \\
\hline DZ465_R & .349 & 3 & . & .832 & 3 & .194 \\
\hline DZ470_L & .327 & 3 & . & .872 & 3 & .302 \\
\hline DZ470_R & .352 & 3 & . & .826 & 3 & .177 \\
\hline DZ476_L & .176 & 3 & . & 1.000 & 3 & .986 \\
\hline DZ476_R & .201 & 3 & . & .994 & 3 & .857 \\
\hline DZ508_L & .186 & 3 & . & .998 & 3 & .919 \\
\hline DZ508_R & .333 & 3 & . & .862 & 3 & .273 \\
\hline
\end{tabular}

\subsection{Pengukuran Carrier Roller}

Tabel 5 menunjukkan hasil uji normalitas data terhadap pengukuran carrier roller front, sedangkan Tabel 6 menunjukkan hasil uji normalitas data terhadap pengukuran carrier roller rear.

Tabel 5. Hasil Uji Normalitas Data Terhadap Pengukuran Carrier Roller Front

Tests of Normality

\begin{tabular}{|c|c|c|c|c|c|c|}
\hline & \multicolumn{3}{|c|}{ Kolmogorov-Smimov" } & \multicolumn{3}{|c|}{ Shapiro-iứllk } \\
\hline & Statistic & $d f$ & $\mathrm{Sig}$ & Statistic & $d f$ & Sig. \\
\hline DZ401_L & .215 & 3 & . & .989 & 3 & .800 \\
\hline DZ401_R & .280 & 3 & . & .938 & 3 & .520 \\
\hline DZ412_L & .385 & 3 & . & .750 & 3 & .000 \\
\hline DZ412_R & .243 & 3 & . & .972 & 3 & .679 \\
\hline DZ488_L & .358 & 3 & . & .812 & 3 & .144 \\
\hline DZ488_R & .253 & 3 & . & .964 & 3 & .637 \\
\hline DZ452_L & .204 & 3 & . & .993 & 3 & .843 \\
\hline DZ452_R & .362 & 3 & . & .803 & 3 & .122 \\
\hline DZ453_L & .183 & 3 & . & .999 & 3 & .934 \\
\hline DZ453_R & .237 & 3 & . & .977 & 3 & .706 \\
\hline DZ459_L & .368 & 3 & . & .790 & 3 & .092 \\
\hline DZ459_R & .360 & 3 & . & .809 & 3 & .135 \\
\hline DZ460_L & .260 & 3 & . & .958 & 3 & .608 \\
\hline DZ460_R & .322 & 3 & . & .880 & 3 & .324 \\
\hline DZ465_L & .221 & 3 & . & .986 & 3 & .773 \\
\hline DZ465_R & .385 & 3 & . & .750 & 3 & .000 \\
\hline DZ470_L & .352 & 3 & . & .825 & 3 & .176 \\
\hline DZ470_R & .304 & 3 & . & .908 & 3 & .410 \\
\hline DZ476_L & .311 & 3 & . & .897 & 3 & .376 \\
\hline DZ476_R & .262 & 3 & . & .956 & 3 & .598 \\
\hline DZ508_L & .336 & 3 & . & .857 & 3 & .258 \\
\hline DZ508_R & .291 & 3 & . & .925 & 3 & .471 \\
\hline
\end{tabular}


Tabel 6. Hasil Uji Normalitas Data Terhadap Pengukuran Carrier Roller Rear

Tests of Normality

\begin{tabular}{|c|c|c|c|c|c|c|}
\hline & \multicolumn{3}{|c|}{ Kolmogorov-Smimov" } & \multicolumn{3}{|c|}{ Shapiro-iugilk } \\
\hline & Statistic & df & Sig. & Statistic & df & $\mathrm{Sig}$. \\
\hline$\overline{D Z 401 \_L}$ & .196 & 3 & . & .996 & $\overline{3}$ & .878 \\
\hline DZ401_R & .385 & 3 & . & .750 & 3 & .000 \\
\hline DZ412_L & .243 & 3 & . & .972 & 3 & .678 \\
\hline $\mathrm{DZ412}$ _R & .219 & 3 & . & .987 & 3 & .780 \\
\hline DZ488_L & .385 & 3 & . & .750 & 3 & .000 \\
\hline DZ488_R & .327 & 3 & . & .871 & 3 & 299 \\
\hline DZ452_L & .232 & 3 & . & .980 & 3 & .726 \\
\hline DZ452_R & .253 & 3 & . & 964 & 3 & .637 \\
\hline DZ453_L & .298 & 3 & . & 916 & 3 & .438 \\
\hline DZ453_R & .385 & 3 & . & .750 & 3 & .000 \\
\hline DZ459_L & .383 & 3 & . & .755 & 3 & .012 \\
\hline DZ459_R & .224 & 3 & 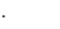 & 985 & 3 & .762 \\
\hline DZ460_L & 299 & 3 & . & .915 & 3 & .434 \\
\hline DZ460_R & .324 & 3 & $\cdot$ & .878 & 3 & .317 \\
\hline DZ465_L & 338 & 3 & . & .852 & 3 & .247 \\
\hline DZ465_R & .258 & 3 & . & .960 & 3 & .616 \\
\hline DZ470_L & .243 & 3 & . & .972 & 3 & .681 \\
\hline DZ470_R & .235 & 3 & . & .978 & 3 & .713 \\
\hline DZ476_L & .280 & 3 & . & .938 & 3 & .519 \\
\hline DZ476_R & .303 & 3 & . & .908 & 3 & .413 \\
\hline DZ508_L & .281 & 3 & 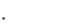 & .936 & 3 & .512 \\
\hline DZ508_R & .313 & 3 & . & .895 & 3 & .370 \\
\hline
\end{tabular}

Berdasarkan hasil uji normalitas data baik pada komponen carrier roller front maupun rear, menunjukan bahwa mayoritas data memiliki nilai signifikan $>0,05$. Dengan demikian hasil pengukuran carrier roller baik front maupun rear adalah meyakinkan atau dengan kata lain alat dan metode pengukuran yang digunakan sudah tepat dan benar.

\subsection{Pengukuran Idler}

Hasil uji normalitas data terhadap pengukuran Idler dapat dilihat pada Tabel 7.

Dari hasil uji normalitas data sebagaimana tersaji pada Tabel 7 , ada 8 data yang memiliki angka signifikan $>0,05$ sedangkan $60 \%$ data menunjukan angka signifikan $<0,05$. Hal ini menunjukan bahwa hasil pengukuran komponen Idler tidak meyakinkan, untuk itu perlu dilakukan evaluasi lebih mendalam agar dapat terungkap permasalahan sebenarnya, apakah alat atau metode pengukuran yang tidak tepat, atau memang laju tingkat keausan komponen idler yang tidak normal.
Tabel 7. Hasil Uji Normalitas Data Terhadap Pengukuran Idler

Tests of Normality

\begin{tabular}{|l|r|r|l|r|r|r|}
\hline & \multicolumn{3}{|c|}{ Kolmogorov-Smimov } & \multicolumn{3}{|c|}{ Shapiro-iúllle } \\
\cline { 2 - 7 } & Statistic & df & Sig. & Statistic & df & Sig. \\
\hline DZ401_L & .385 & 3 &. & .750 & 3 & .000 \\
DZ401_R & .385 & 3 &. & .750 & 3 & .000 \\
DZ412_L & .347 & 3 &. & .836 & 3 & .204 \\
DZ412_R & .347 & 3 &. & .836 & 3 & .204 \\
DZ488_L & .385 & 3 &. & .750 & 3 & .000 \\
DZ488_R & .385 & 3 &. & .750 & 3 & .000 \\
DZ452_L & .385 & 3 &. & .750 & 3 & .000 \\
DZ452_R & .385 & 3 &. & .750 & 3 & .000 \\
DZ453_L & .385 & 3 &. & .750 & 3 & .000 \\
DZ453_R & .385 & 3 &. & .750 & 3 & .000 \\
DZ459_L & .286 & 3 &. & .931 & 3 & .492 \\
DZ459_R & .286 & 3 &. & .931 & 3 & .492 \\
DZ460_L & .368 & 3 &. & .791 & 3 & .092 \\
DZ460_R & .368 & 3 &. & .791 & 3 & .092 \\
DZ465_L & .385 & 3 &. & .750 & 3 & .000 \\
DZ465_R & .385 & 3 &. & .750 & 3 & .000 \\
DZ470_L & .305 & 3 &. & .905 & 3 & .403 \\
DZ470_R & .305 & 3 &. & .905 & 3 & .403 \\
DZ476_L & .385 & 3 &. & .750 & 3 & .000 \\
DZ476_R & .385 & 3 &. & .750 & 3 & .000 \\
DZ508_L & .385 & 3 &. & .750 & 3 & .000 \\
DZ508_R & .385 & 3 &. & .750 & 3 & .000 \\
\hline
\end{tabular}

a. Lilliefors Significance Correction

\subsection{Pengukuran Sprocket}

Hasil uji normalitas data terhadap pengukuran sprocket dapat dilihat pada Tabel 8 .

Tabel 8. Hasil Uji Normalitas Data Terhadap Pengukuran Sprocket

\begin{tabular}{|c|c|c|c|c|c|c|}
\hline & \multicolumn{3}{|c|}{ Kolmogorov-Smimov" } & \multicolumn{3}{|c|}{ Shapiro-iúillk } \\
\hline & Statistic & $\mathrm{df}$ & Sig. & Statistic & $d f$ & $\mathrm{Sig}$. \\
\hline$\overline{\text { DZ401_L }}$ & .352 & 3 & . & .825 & 3 & .175 \\
\hline DZ401_R & .352 & 3 & . & .825 & 3 & .175 \\
\hline DZ412_L & .385 & 3 & . & .750 & 3 & .000 \\
\hline DZ412_R & .385 & 3 & . & .750 & 3 & .000 \\
\hline DZ488_L & .385 & 3 & . & .750 & 3 & .000 \\
\hline DZ488_R & .385 & 3 & . & .750 & 3 & .000 \\
\hline DZ452_L & .175 & 3 & . & 1.000 & 3 & 1.000 \\
\hline DZ452_R & .175 & 3 & . & 1.000 & 3 & 1.000 \\
\hline DZ453_L & .385 & 3 & . & .750 & 3 & .000 \\
\hline DZ453_R & .385 & 3 & . & .750 & 3 & .000 \\
\hline DZ459_L & .385 & 3 & . & .750 & 3 & .000 \\
\hline DZ459_R & .385 & 3 & . & .750 & 3 & .000 \\
\hline DZ460_L & .183 & 3 & . & .999 & 3 & .932 \\
\hline DZ460_R & .183 & 3 & . & .999 & 3 & .932 \\
\hline DZ465_L & .385 & 3 & . & .750 & 3 & .000 \\
\hline DZ465_R & .385 & 3 & . & .750 & 3 & .000 \\
\hline DZ470_L & .357 & 3 & . & .814 & 3 & .149 \\
\hline DZ470_R & .357 & 3 & . & .814 & 3 & .149 \\
\hline DZ476_L & .385 & 3 & . & .750 & 3 & .000 \\
\hline DZ476_R & .385 & 3 & . & .750 & 3 & .000 \\
\hline
\end{tabular}

a. Lilliefors Significance Correction

Hasil uji normalitas data sebagaimana tersaji dalam Tabel 8 menunjukan bahwa nilai signifikan $>0,05$ hanya ada 8 data, artinya mayoritas tidak memenuhi syarat normalitas data, dengan demikian hasil pengukuran 
komponen sprocket tidak meyakinkan, oleh karena itu perlu dilakukan evaluasi yang lebih mendalam untuk mendapatkan informasi yang lebih akaurat tentang apakah alat atau metode pengukuran sprocket yang perlu diperbaiki, ataukah memang terdapat laju keausan sprocket yang tidak normal.

\subsection{Pengukuran Track Roller}

Undercarriage bulldozer Komatsu D375A-5 memiliki 7 buah track roller pada sisi kiri dan 7 track roller pada sisi kanan. Hasil uji normalitas data terhadap pengukuran masing-masing track roller dapat dilihat pada Tabel 9.

Tabel 9. Hasil Uji Normalitas Data Terhadap Pengukuran Track Roller

\begin{tabular}{|c|c|c|c|}
\hline $\begin{array}{c}\text { Nama } \\
\text { komponen }\end{array}$ & $\begin{array}{c}\text { Jumlah } \\
\text { data yang } \\
\text { nilai } \\
\text { Signifikan } \\
<0,05\end{array}$ & $\begin{array}{c}\text { Prosentase } \\
\text { data yang } \\
\text { nilai } \\
\text { Signifikan } \\
<0,05\end{array}$ & $\begin{array}{c}\text { Prosentase } \\
\text { data yang } \\
\text { nilai } \\
\text { Signifikan } \\
>0,05\end{array}$ \\
\hline Track Roller-1 & 4 & $18 \%$ & $82 \%$ \\
\hline Track Roller-2 & 4 & $18 \%$ & $82 \%$ \\
\hline Track Roller-3 & 2 & $9 \%$ & $91 \%$ \\
\hline Track Roller-4 & 2 & $9 \%$ & $91 \%$ \\
\hline Track Roller-5 & 1 & $5 \%$ & $95 \%$ \\
\hline Track Roller-6 & 3 & $14 \%$ & $86 \%$ \\
\hline Track Roller-7 & 2 & $9 \%$ & $91 \%$ \\
\hline
\end{tabular}

Berdasarkan Tabel 9 menunjukan bahwa mayoritas hasil uji normalitas data terhadap hasil pengukuran track roller memiliki nilai signifikan $>0,05$. Dengan demikian hasil pengukuran track roller adalah meyakinkan, atau dengan kata lain penggunaan alat dan metode pengukuran track roller sudah tepat dan benar.

\section{Kesimpulan}

Hasil pengukuran komponen
undercarriage pada bulldozer Komatsu
D375A-5 yang dioperasikan di area
pertambangan Site Batukajang tidak semuanya
meyakinkan.

Adapun hasil pengkuran komponen undercarriage yang mayoritas memiliki angka signifikan $<0,05$ (tidak meyakinkan) antara lain hasil pengukuran komponen link-pitch, idler, dan sprocket.

\section{Saran}

Perlu dilakukan penelitian lebih lanjut untuk menginvestigasi apakah alat atau metode yang dilakukan dalam pengukuran komponen link-pitch, idler, dan sprocket telah dilakukan secara tepat dan benar. Selain itu, untuk mengetahui apakah terjadi laju keausan yang tidak normal pada komponen link-pitch, idler, dan sprocket.

\section{Daftar Pustaka}

[1] Caterpillar,. (2011) Cat Undercarriage Management System, Cat, Caterpillar USA.

[2] D. M. Levine, D. F. Stephan, T. C. Krehbiel, dan M. L. Berenson, "The Normal Distribution," pada Statistics for Managers Using Microsoft Excel, Edisi Kelima, Upper Saddle River, New Jersey: Prentice-Hall, 2008, hal. 201.

[3] Komatsu,. (2014) Undercarriage System, Komatsu Europe International NV Mechelsesteenweg 586, Belgium.

[4] Sugiyono, (2007) Statistika untuk Penelitian, CV Alfabeta, Bandung.

[5] West-Track, Undercarriage Handbook, Westport, New Zealand. 